\title{
Erratum to: Women and corruption: evidence from multinational panel data
}

\author{
$\mathrm{Yu} \mathrm{Hao}^{1} \cdot$ Chun-Ping Chang ${ }^{2,3} \cdot \mathrm{Zao} \mathrm{Sun}^{3}$
}

\section{Erratum to: Qual Quant DOI 10.1007/s11135-017-0530-7}

The original publication of an article includes error in the reference citation. The reference "Haselmayer and Jenny (2016)" cited in Table 1 and in the reference list should be omitted.

The online version of the original article can be found under doi:10.1007/s11135-017-0530-7.

Chun-Ping Chang

cpchang@g2.usc.edu.tw

Yu Hao

haoyuking@bit.edu.cn

Zao Sun

sunz@mail.xjtu.edu.cn

1 School of Management and Economics, Beijing Institute of Technology, Beijing 100081,

People's Republic of China

2 Department of Marketing Management, Shih Chien University at Kaohsiung, Kaohsiung 845, Taiwan

3 School of Economics and Finance, Xi' an Jiaotong University, Xi' an 710049, Shaanxi, People's Republic of China 